Supporting Information

\title{
Self-powered Filterless Narrow-band $p$ - $n$ Heterojunction Photodetector for Low Background Limited Near-infrared Image Sensor Application
}

Li Wang,,$^{\dagger}$ Zhen Li,${ }^{\dagger}$ Ming Li, ${ }^{\dagger}$ Shao Li,${ }^{\ddagger}$ Yingchun Lu, ${ }^{\dagger}$ Ning $Q i,{ }^{\dagger}$ Jian Zhang,,${ }^{\S}$ Chao Xie,${ }^{\dagger}$ Chunyan $W u,{ }^{\dagger}$ Lin-Bao Luo $^{\dagger *}$

†School of Electronic Science and Applied Physics, Hefei University of Technology, Hefei 230009, China

¥ State Key Laboratory of Metastable Materials Science \& Technology, Yanshan University Qinhuangdao 066004, China

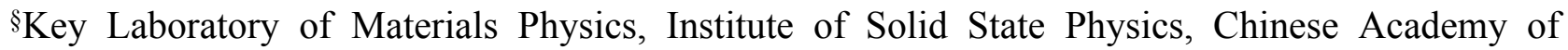
Sciences, Hefei 230031, China

* Correspondence should be addressed to luolb@hfut.edu.cn (L. B. Luo) and zhangiian@issp.ac.cn (J. Zhang) 
Figure S1. I-V curves for (a) Ag/CuGaTe $2 / \mathrm{Ag}$ structure and (b) In-Ga/Si/In-Ga structure.

Figure S2. Raman spectra of $\mathrm{CuGaTe}_{2}$ film.

Figure S3. Wavelength-dependent responsivity of the $\mathrm{CuGaTe}_{2}$ film measured at $5 \mathrm{~V}$.

Figure S4. UPS analysis of the $\mathrm{CuGaTe}_{2}$ film. The work function of the $\mathrm{CuGaTe}_{2}$ film can be determined to be $4.47 \mathrm{eV}$.

Figure S5. Photoresponse switching behavior of $\mathrm{CuGaTe}_{2} /$ silicon pn junction at varying voltages from -0.5 to $-3.0 \mathrm{~V}$.

Table S1. Composition of $\mathrm{CuGaTe}_{2}$ films measured with energy dispersive spectroscopy.

Table S2. The permittivity, impurity concentration, work function of $\mathrm{CuGaTe}_{2}$ and $\mathrm{Si}$. 


\section{Calculation of the depletion region:}

The width of depletion region of $\mathrm{CuGaTe}_{2}$ film can be calculated according to the following formula:

$$
\mathrm{W}_{p}=\sqrt{\frac{2 \varepsilon_{s p} \varepsilon_{s n} \phi_{b i}}{q N_{A}\left(\varepsilon_{s n}+\frac{N_{A}}{\mathrm{~N}_{\mathrm{D}}} \varepsilon_{s p}\right)}}
$$

And $\quad \phi_{\mathrm{bi}}=\frac{E_{F n}-E_{F p}}{q}$

where $\varepsilon_{\mathrm{sp},} \varepsilon_{\mathrm{sn}}, N_{\mathrm{A}}, N_{\mathrm{D}}, E_{\mathrm{Fp}}, E_{\mathrm{Fn}}$ are dielectric constant, impurity concentration, fermi level of CGT and $\mathrm{Si}, q$ is the elementary electronic charge, $\phi_{\mathrm{bi}}$ is the contact potential difference between $\mathrm{CuGaTe}_{2}$ and Si. Since the difference between fermi levels of two materials is equal to the difference between their work functions, formula (2) can be written as $\phi_{\mathrm{bi}}=\frac{\mathrm{W}_{F n}-\mathrm{W}_{F p}}{q}$

The work function of the $\mathrm{CuGaTe}_{2}$ film can be determined to be $4.47 \mathrm{eV}$ from the ultraviolet photoemission spectroscopy (UPS) measurement (Fig.S3). Based on this, the width of depletion region in $\mathrm{CuGaTe}_{2}$ is evaluated to be $0.081 \mathrm{~nm}$, while that in $\mathrm{Si}$ is $405 \mathrm{~nm}$. Related parameter can be found in Table S2. The impurity concentration of $\mathrm{CuGaTe}_{2}$ was obtained by using Hall effect measurement. And the doping concentration of silicon is quoted from literature, ${ }^{[1]}$ with work-function calculated to be $4.26 \mathrm{eV}$ according to formula: $\mathrm{W}_{\mathrm{s}}=\chi+\mathrm{E}_{n}, \mathrm{E}_{\mathrm{n}}=k_{0} T \ln \frac{N_{c}}{n_{0}}(4)$, where $\chi, \mathrm{N}_{c}, \mathrm{n}_{0}$ is the electron affinity, conduction-band edge density of states, and carrier concentration, respectively. ${ }^{[2]}$ Moreover the permittivity of $\mathrm{CuGaTe}_{2}$ and $\mathrm{Si}$ were calculated based on the relative dielectric constant quoted from references. ${ }^{[3][4]}$

\section{The Ohmic electrodes of $\mathrm{CuGaTe}_{2}$ film and n-type silicon}

Figure S1 shows that the I-V curves of $\mathrm{Ag} / \mathrm{CuGaTe}_{2} / \mathrm{Ag}$ and $\mathrm{In}-\mathrm{Ga} / \mathrm{Si} / \mathrm{In}-\mathrm{Ga}$ structures are both near-linear, indicating the formation of Ohmic contact (Figure S1). The Ohmic contact between $\mathrm{Ag}$ and $\mathrm{CuGaTe}_{2}$ should be the result of the high electrical conductivity $\left(10^{-3}-10^{-2} \Omega \cdot \mathrm{cm}\right)$ 
of $\mathrm{CuGaTe}_{2}{ }^{[5]}$ and the similar work-function of $\mathrm{Ag}(4.3 \mathrm{eV}){ }^{[6]}$ and $\mathrm{CuGaTe}_{2}(4.47 \mathrm{eV})$. Moreover, the achievement of Ohmic contact between In-Ga alloy and $n$-type Si should be due to the low work-function of In-Ga ally(4.2eV) ${ }^{[7]}$, which is often used as Ohmic electrodes materials of $n$-type $\mathrm{Si}^{[8]-[12]}$.

(a)

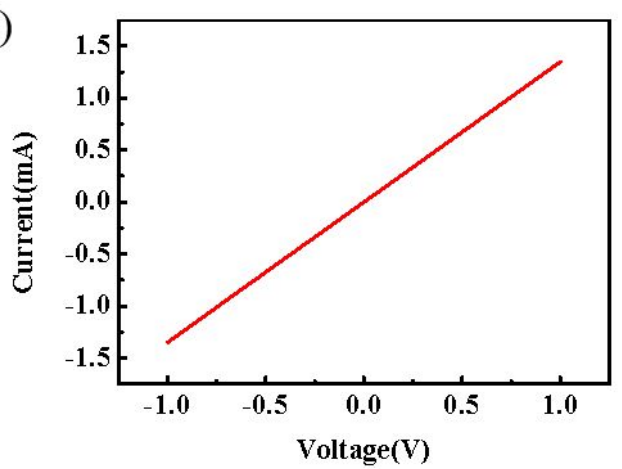

(b)

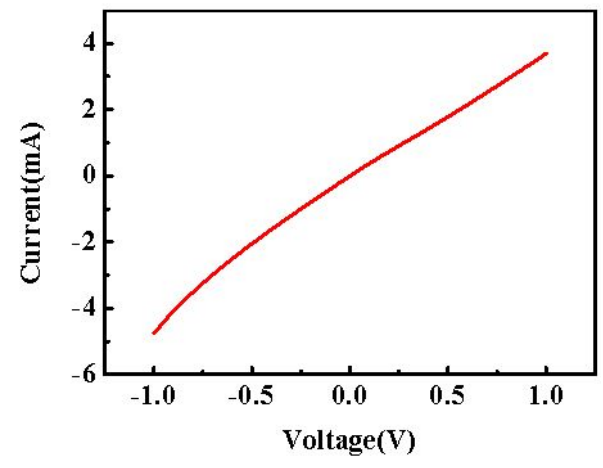

Figure S1. $I-V$ curves for (a) $\mathrm{Ag} / \mathrm{CuGaTe}_{2} / \mathrm{Ag}$ structure and (b) $\mathrm{In}-\mathrm{Ga} / \mathrm{Si} / \mathrm{In}-\mathrm{Ga}$ structure.

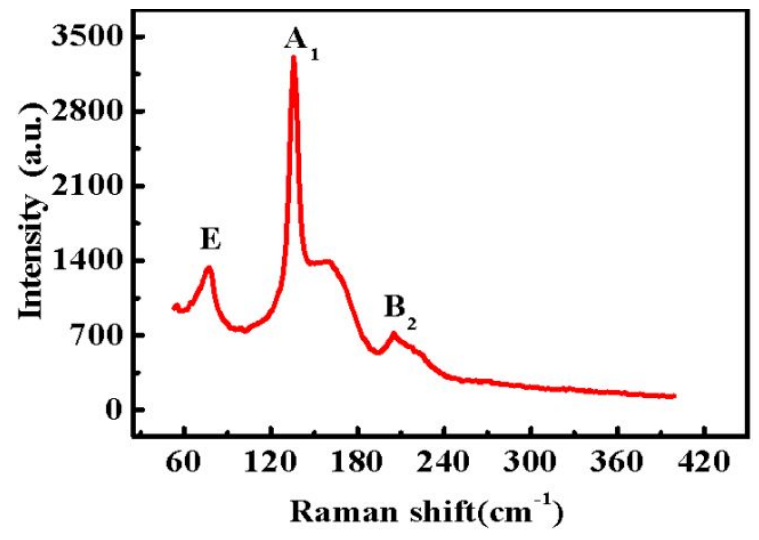

Figure S2. Raman spectra of $\mathrm{CuGaTe}_{2}$ film.

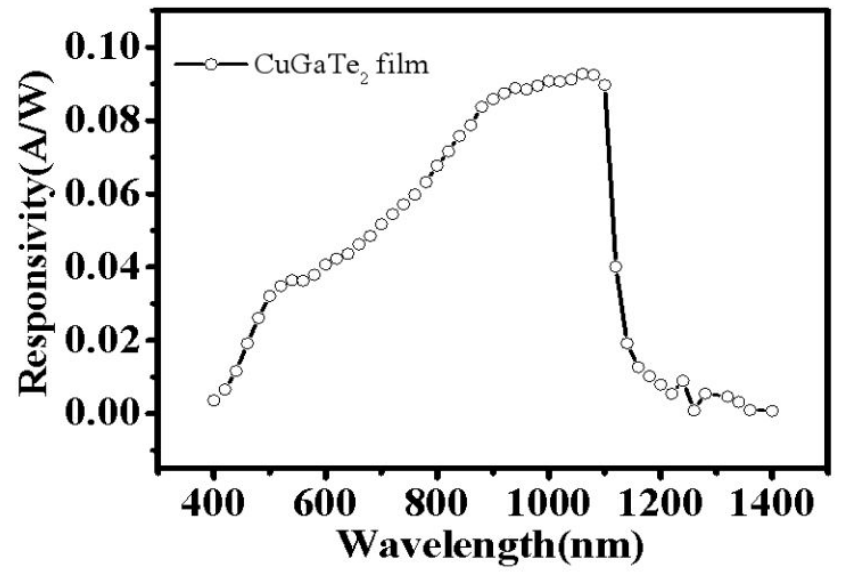

Figure S3. Wavelength-dependent responsivity of the $\mathrm{CuGaTe}_{2}$ film. 


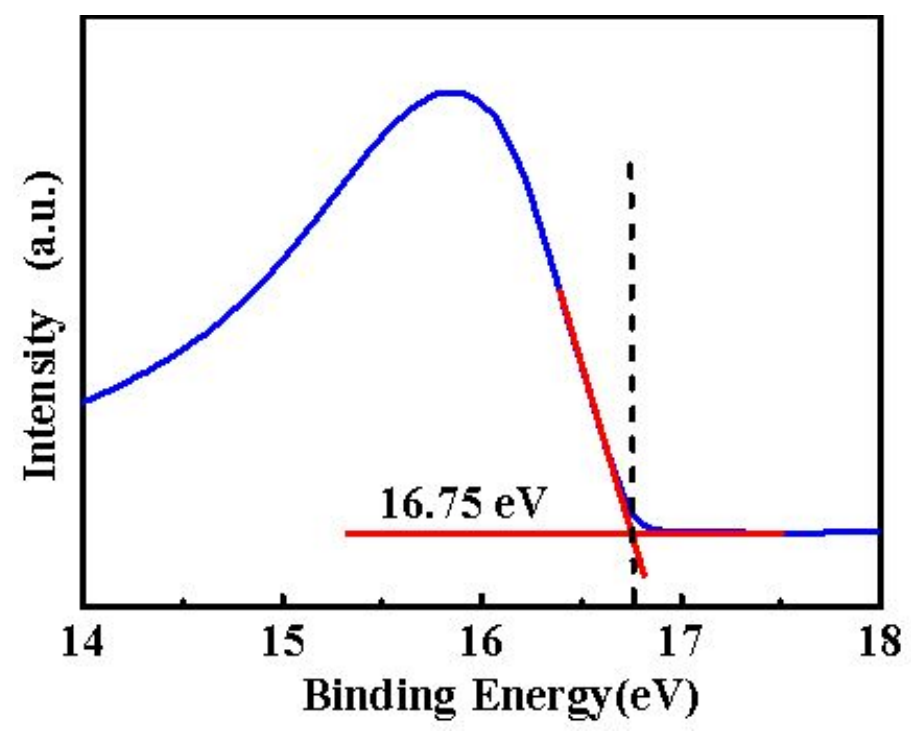

Figure S4. UPS analysis of the $\mathrm{CuGaTe}_{2}$ film. The work function of the $\mathrm{CuGaTe}_{2}$ film can be determined to be $4.47 \mathrm{eV}$.

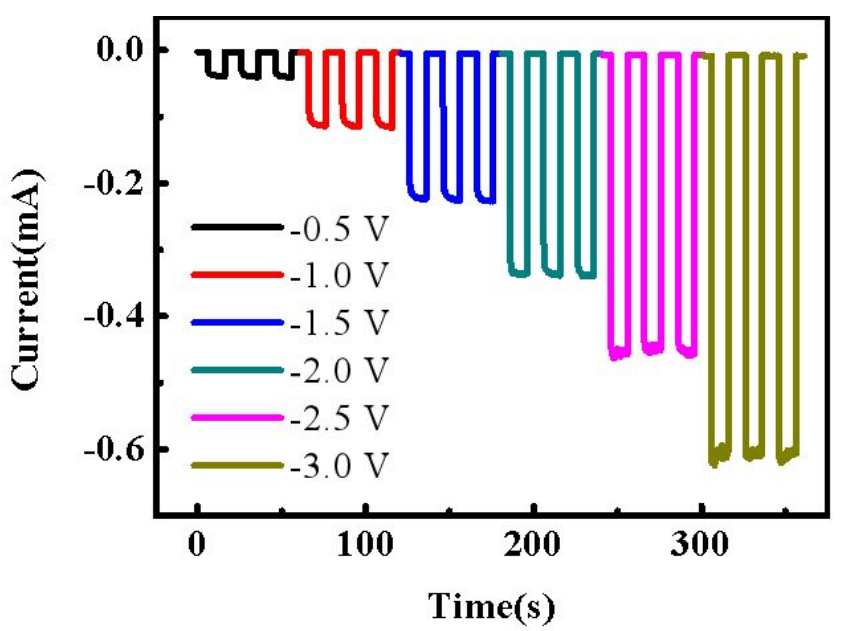

Figure S5. Photoresponse switching behavior of $\mathrm{CuGaTe}_{2} /$ silicon pn junction at varying voltages from -0.5 to $-3.0 \mathrm{~V}$.

Table S1. Composition of $\mathrm{CuGaTe}_{2}$ films measured with energy dispersive spectroscopy.

\begin{tabular}{ccc}
\hline Elements & $\begin{array}{c}\text { Weight } \\
{[\%]}\end{array}$ & $\begin{array}{c}\text { Atomic } \\
{[\%]}\end{array}$ \\
\hline $\mathrm{Cu}$ & 15.73 & 24.03 \\
$\mathrm{Ga}$ & 18.81 & 26.18 \\
$\mathrm{Te}$ & 65.46 & 49.79 \\
$\mathrm{Total}$ & 100 & 100 \\
\hline
\end{tabular}

Table S2. The permittivity, impurity concentration, work function of $\mathrm{CuGaTe}_{2}$ and $\mathrm{Si}$. 


\begin{tabular}{cccc}
\hline Materials & $\begin{array}{c}\text { Permittivity } \\
{[\mathrm{F} / \mathrm{m}]}\end{array}$ & $\begin{array}{c}\text { Impurity concentration } \\
{\left[\mathrm{cm}^{-3}\right]}\end{array}$ & $\begin{array}{c}\text { Work function } \\
{[\mathrm{eV}]}\end{array}$ \\
\hline $\mathrm{Si}$ & $1.05 \times 10^{-10}$ & $8 \times 10^{14}$ & 4.26 \\
$\mathrm{CuGaTe}_{2}$ & $7.97 \times 10^{-11}$ & $4.02 \times 10^{18}$ & 4.47 \\
\hline
\end{tabular}

\section{Reference:}

[1] Masetti, G.; Severi, M.; Solmi,S. Modeling of Carrier Mobility Against Carrier Concentration in Arsenic-, Phosphorus-, and Boron-Doped Silicon. IEEE Trans. on Electron 1983, 30, 7, 764-765.

[2] Grundmann, M. In The Physics of Semiconductors; Springer-Verlag: Berlin, 2010; pp 187.

[3] El-Hady, S. A. A.; Mansour, B. A.; Moustafas, H. Growth and Spectral Dependence of the Absorption Coefficient of CuGaTe Thin Films. phys. stat. sol. (a) 1995,149, 601-609

${ }^{[4]}$ Sze, S. M.; Ng, K. K. In Physics of Semiconductor Devices; John Wiley \& Sons: New York, 2006; pp 788-789.

[5] Plirdpring, T.; Kurosaki, K.; Kosuga, A.; Day, T.; Firdosy, S.; Ravi, V.; Snyder, G. J.; Harnwunggmoung, A.; Sugahara, T.; Ohishi, Y.; Muta, H.; Yamanaka, S. Chalcopyrite $\mathrm{CuGaTe}_{2}$ : A High-Efficiency Bulk Thermoelectric Material. Adv. Mater. 2012, 24, 3622-3626

[6] Giovannetti, G.; Khomyakov, P. A.; Brocks, G.; Karpan,V. M.; Brink, J. V. D.; Kelly, P. J. Doping Graphene with Metal Contacts. Phys. Rev. Lett. 2008,101, 2, 026803

[7] Xie,C.; Nie, Biao; Zeng, L.H.; Liang, F. X.; Wang, M. Z.; Luo, L.B.; Feng, M.; Yu, Y. Q.; Wu, C. Y.; Wu, Y. C.; Yu,S. H. Core-Shell Heterojunction of Silicon Nanowire Arrays and Carbon Quantum Dots for Photovoltaic Devices and Self-Driven Photodetectors. ACS Nano 2014, 8, 4, 4015 - 4022

${ }^{[8]}$ Shin, D. H.; Jung, D. H.; Kim, Y. C.; Lee, C. G.; Wang ,X. L.; Choi, S. H. High-Speed Heterojunction Photodiodes Made of Single- or Multiplelayer MoS2 Directly-Grown on Si Quantum Dots.J. Alloy Compd. 2020, 820,153074

${ }^{[9]}$ Lu, Z. J.; Xu, Y.; Yu, Y. Q.; Xu, K. W.; Mao, Jie; Xu, G. B.; Ma, Y. M.;Wu, D.; Jie, J. S. Ultrahigh Speed and Broadband Few-Layer MoTe2/Si 2-3D Heterojunction-Based Photodiodes Fabricated by Pulsed Laser Deposition, Adv. Funct. Mater. 2020, 1907951

${ }^{[10]}$ Chen, L.; Tian, W.; Min, L. L.; Cao, F. R.; Li, L. Si/CuIn0.7Ga0.3Se2 Core - Shell Heterojunction for Sensitive and Self-Driven UV-vis-NIR Broadband Photodetector. Adv. Optical Mater. 2019, 1900023

${ }^{[11]}$ Wu, E. P.; Wu, D.;Jia, C.; Wang, Y. G.; Yuan, H. Y.; Zeng, L. H.; Xu,T. T.;Shi, Z.F.; Tian,Y. T.; Li, X. J. In Situ Fabrication of 2D WS2/Si Type-II Heterojunction for Self-Powered Broadband Photodetector with Response up to Mid-Infrared,ACS Photonics 2019, 6, 565-572

${ }^{[12]}$ Zhang,H. B.; Zhang, X. J.; Liu, C.; Lee, S.T.;Jie, J. S. High-Responsivity, High-Detectivity, Ultrafast Topological Insulator Bi2Se3/Silicon Heterostructure Broadband Photodetectors. ACS Nano 2016, 10, 5113-5122 